\title{
Association between teeth loss and nasogastric tube feeding dependency in older adults from Taiwan: a retrospective cohort study
}

\author{
Chun-Chieh Wang ${ }^{1,2}$, Yu-Yen Chen 3,4,5,6,7, Kuo-Chuan Hung ${ }^{8}$, Shang-Jung Wu ${ }^{9,10}$, Yung-Feng Yen ${ }^{11,12,13}$,
} Chu-Chieh Chen ${ }^{11^{*+}}$ and Yun-Ju Lai $i^{3,11,14,15^{*+}}$

\begin{abstract}
Background: To examine the association between teeth loss and nasogastric tube feeding dependency in older people.

Methods: The National Health Interview Survey (NHIS) 2005, 2009, and 2013 in Taiwan. Participants were selected by a multistage stratified sampling method and baseline characteristics, including socioeconomic status and health habits, were obtained by well-trained interviewers. The NHIS was linked with the National Health Insurance research database 2000-2016 and the National Deaths Dataset, which contains all the medical information of ambulatory and inpatient care. Cox regression was used to examine the association between the number of teeth lost and nasogastric tube feeding dependency.

Results: There were 6165 adults older than 65 years old enrolled in the analysis, with 2959 male (48\%) and the mean (SD) age was 73.95(6.46) years old. The mean follow-up duration was 6.5(3.3) years. Regarding the teeth loss categories, 1660 (26.93\%), 2123 (34.44\%), and 2382 (38.64\%) of participants were categorized as having no teeth loss, loss of 1-9 teeth, and loss of 10-28 teeth, respectively. During 39,962 person-years of follow-up, new-onset nasogastric feeding dependency was recognized in 220(13.25\%), 256(12.06\%), and 461(19.35\%) participants who were categorized as having no teeth loss, loss of 1-9 teeth, and loss of 10-28 teeth, respectively. Kaplan-Meier curves demonstrated significant findings (Log-rank $P<0.01$ ). After potential confounders were adjusted, compared with those without teeth loss, older adults who had lost 10-28 teeth had significantly increased risks of occurrence nasogastric feeding dependency (AHR, 1.31; 95\% Cl, 1.05-1.62; $p$-value =0.02). Furthermore, a significant dose-response relation between the number of teeth lost and increased risk of nasogastric feeding was found ( $p$ for trend $<0.01$ ).
\end{abstract}

\footnotetext{
*Correspondence: chuje@ntunhs.edu.tw; lailai841081@yahoo.com.tw

${ }^{\dagger}$ Chu-Chieh Chen and Yun-Ju Lai contributed equally to this work.

${ }^{11}$ Department of Health Care Management, National Taipei University of Nursing and Health Sciences, No.365, Ming-te Road, Peitou District, Taipei City 112, Taiwan

${ }^{15}$ Division of Endocrinology and Metabolism, Department of Internal Medicine, Puli Branch of Taichung Veterans General Hospital, No.1, Rongguang Rd, Puli Township, Nantou County 545, Taiwan

Full list of author information is available at the end of the article
}

(C) The Author(s) 2021. Open Access This article is licensed under a Creative Commons Attribution 4.0 International License, which permits use, sharing, adaptation, distribution and reproduction in any medium or format, as long as you give appropriate credit to the original author(s) and the source, provide a link to the Creative Commons licence, and indicate if changes were made. The images or other third party material in this article are included in the article's Creative Commons licence, unless indicated otherwise in a credit line to the material. If material is not included in the article's Creative Commons licence and your intended use is not permitted by statutory regulation or exceeds the permitted use, you will need to obtain permission directly from the copyright holder. To view a copy of this licence, visit http://creativecommons.org/licenses/by/4.0/. The Creative Commons Public Domain Dedication waiver (http://creativeco mmons.org/publicdomain/zero/1.0/) applies to the data made available in this article, unless otherwise stated in a credit line to the data. 
Conclusions: Older adults who had lost 10-28 teeth had a significantly increased risk of nasogastric tube feeding dependency. Early identification of the oral disease is crucial for the prevention of the occurrence of teeth loss and the following nutrition problems, which would reduce risk of nasogastric tube feeding dependency.

Keywords: Teeth loss, Nasogastric tube feeding, Older people

\section{Key points}

1. Older adults who had lost $10-28$ teeth had a significantly increased risk of nasogastric tube feeding dependency.

2. Older age, male gender, consuming vegetables and fruits less than 5-7 days/week, heart failure, stroke, and cancer were also significant risk factors of nasogastric tube feeding dependency.

3. It is important to maintain good oral health to prevent loss of teeth and further occurrence of nasogastric tube feeding dependency.

\section{Background}

In Taiwan's aging society, dysphagia is a common problem among older adults such as older nursing home residents [1], older adults admitted to the hospital [2], patients with stroke [3], and even older adults who live independently [4]. People with dysphagia and poor nutrition status usually need to supplement with enteral nutrition. Enteral feeding can be carried out by nasogastric, nasal duodenal, and nasojejunal routes. In Taiwan, the most commonly used enteral feeding is nasogastric tube feeding.

According to the report from the Ministry of Health and Welfare Taiwan, the prevalence of nasogastric tube feeding among people older than 65 years is $17.9 \%$ in 2020 (19.8\% in men and $16.2 \%$ in women) [5]. This rate is only $11.6 \%$ in Japan and $6.6 \%$ in Germany. In America, the proportion of nasogastric tube feeding in nursing home residents with advanced dementia declined from $11.7 \%$ in 2000 to $5.7 \%$ in 2014 [6, 7]. In Taiwan, around $99 \%$ residents were covered under the National Health Insurance program [8]. The low cost and convenience for the caregiver to feed the patients cause the high prevalence of nasogastric tube feeding in Taiwan.

However, it was reported that enteral feeding did not prevent aspiration pneumonia, improved bed sore healing, or reduced infection rates, or prolong survival [9]. The presence of nasogastric, nasal duodenal and nasojejunal feeding tubes can also promote negative psychosocial characteristics, such as depression and loss of social contact associated with tube feeding [10].
Any difficulty in the swallowing pathway can be defined as dysphagia. People with anatomical or physical defects in the oral cavity, pharynx, larynx, and esophagus may experience dysphagia. The anatomy and physiology of swallowing changes with increasing age. Loss of muscle mass power and connective tissue elasticity leads to loss of strength and variety of motion [11].

Teeth loss can cause changes in oral anatomy. Previous research reports that dysphagia and swallowing difficulty due to aging are more prevalent in older adults with more teeth loss [12]. However, the association of teeth loss and nasogastric tube feeding dependency is seldom discussed. We thus aimed to discover the association of teeth loss and nasogastric tube feeding dependency by using data from the National Health Interview Survey (NHIS), the National Health Insurance research database and the National Death dataset.

\section{Methods \\ Data collection}

The Health Promotion Administration, Ministry of Health and Welfare in Taiwan performed a national health survey since 2001. The National Health Interview Survey (NHIS) chose participants by the multistage stratified systematic sampling method. Baseline information of socioeconomic status and health habits were collected by well-trained interviewers. The NHIS was conducted every 4 years since 2001 . We used data from the NHIS in 2005, 2009, and 2013. The NHIS was linked with the National Health Insurance research database 2000-2016 and the National Deaths Dataset. The National Health Insurance research database contains all the medical information, including ambulatory and inpatient medical records. This research was approved by the Research Ethics Committee. All methods were performed in accordance with the relevant guidelines and regulations.

\section{Teeth loss}

The number of teeth lost was collected by asking the question "Except wisdom teeth, is there any one tooth been lost or extracted?" and the response item was: 0 . No; 1 . Yes, how many teeth? ; 2. Complete denture. 


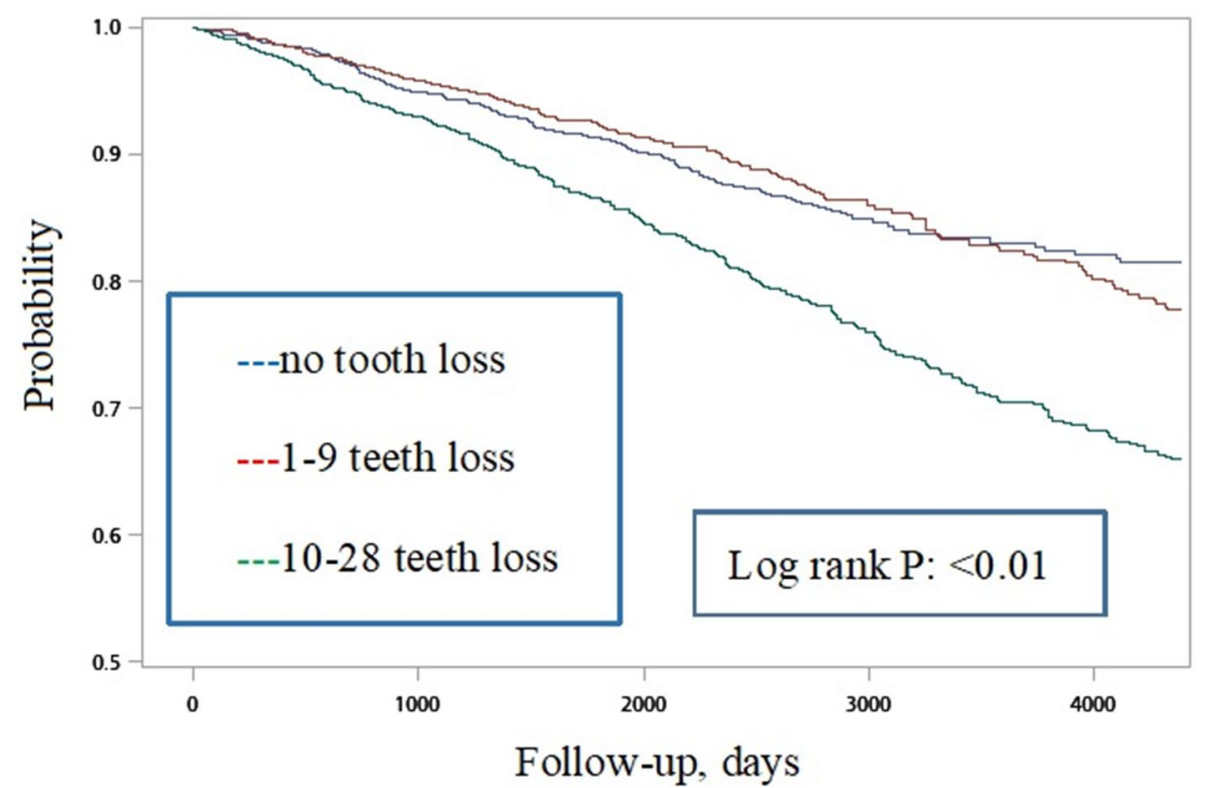

Fig. 1 Kaplan-Meier survival curve estimates for nasogastric feeding dependency among three groups of teeth loss for the older population in Taiwan

\section{Nasogastric tube feeding dependency}

Nasogastric tube feeding dependency was confirmed by the procedure code " $47017 C$ " and " $47018 C$ " from the National Health Insurance research database 20002016. Participants were defined as having nasogastric feeding dependency if the procedure code was coded three or more times in the outpatient or inpatient medical records consecutively in six months.

\section{Potential confounders}

Baseline characteristics of the participants, including socioeconomic status and health habits, were collected by well-trained interviewers. The classification of body mass index was recommended by the Health Promotion Administration of the Ministry of Health and Welfare. Comorbidities were recognized from the National Health Insurance research database 2000-2016. Disease diagnosis was coded with the International Classification of Disease, 9th Revision Clinical Modification (ICD-9-CM). Comorbidity was defined if the diagnosis code was noted in three or more outpatient medical records or one outpatient medical record before the occurrence of nasogastric tube insertion. Comorbidities were documented, including chronic renal failure (ICD-9-CM code 585), heart failure (ICD-9-CM codes 428), liver cirrhosis (ICD-9-CM codes 571.2, 571.5), stroke (ICD-9-CM code 430-438), and cancer (ICD9-CM code 140-208).

\section{Study design}

This was a nationwide retrospective cohort study. We selected older adults aged more than 65 years old from the NHIS 2005, 2009, and 2013. Those compatible with the definition of nasogastric feeding dependency from the NHIRD before the date of interview were excluded. The follow-up period was calculated since the interview date and censored on the date of nasogastric feeding dependency, death, or Dec 31, 2016.

\section{Statistical analysis}

First, survival curves were illustrated. The Kaplan-Meier method with log-rank test was applied to compare the differences across the three categories of teeth loss. Participants with no teeth loss were used as the reference group. Hazard ratios (HRs) and $95 \%$ confidence intervals (CIs) for nasogastric feeding dependency were calculated by Cox proportional-hazards regression models. Data analyses were performed by using SAS 9.4 (SAS Institute, Cary NC).

\section{Results}

There were 7382 participants older than 65 years who took part in the three rounds of the NHIS in 2005, 2009, and 2013. After excluding those with unavailable information on teeth loss $(n=972)$ and those already diagnosed with nasogastric feeding $(n=245)$, 6165 participants were included in the analysis. Among them, 2959 were male (48\%) and the mean (SD) age 
was 73.95(6.46) years old. The mean follow-up duration was 6.5(3.3) years. Figure 1 illustrates the KaplanMeier curves of the three categories of teeth loss, which revealed a significant difference ( $p$-value of log-rank test $<0.001)$.

Table 1 summarizes the baseline characteristics and comorbidities of study participants and the result of the univariate Cox regression model. Regarding the teeth loss categories, 1660 (26.93\%), 2123 (34.44\%), and 2382 (38.64\%) of participants were categorized as having no teeth loss, loss of 1-9 teeth, and loss of 10-28 teeth, respectively. During 39,962 person-years of follow-up, new-onset nasogastric feeding dependency was recognized in 220(13.25\%), 256(12.06\%), and 461(19.35\%) participants who were categorized as having no teeth loss, loss of 1-9 teeth, and loss of 10-28 teeth, respectively. Compared with those with no teeth loss, participants with more teeth loss had increased risks of nasogastric feeding dependency (loss of 1-9 teeth: hazard ratio [HR], 1.03 ; $95 \%$ confidence interval $[\mathrm{CI}], 0.86-1.24 ; p$-value $=0.74$; loss of $10-28$ teeth: HR, 1.73; $95 \% \mathrm{CI}, 1.46-2.07$; $\mathrm{p}$-value $<0.001)$. Older age, male gender, underweight, widowed/divorced/separated, low education level, current and former smokers, lower fruit and vegetable intake, betel nut chewing habit, and those with comorbidities were correlated with a significant risk of nasogastric feeding dependency.

Table 2 summarizes the result of the multivariate Cox regression model. Risk factors associated with the occurrence of nasogastric feeding dependency were identified. After controlling for potential confounders, compared with those with no teeth loss, older people who had lost 10-28 teeth had significantly increased risks of incident nasogastric feeding dependency (AHR, 1.31; 95\% CI, 1.05-1.62; $p$-value $=0.02$ ). A significant dose-response association between the number of teeth lost and increased risk of nasogastric feeding was found using the trend test ( $\mathrm{p}$ for trend $<0.01$ ). Other variables that increased the risk of incident nasogastric feeding dependency included age, male gender, consuming vegetables and fruits less than 5-7 days/week, heart failure, stroke, and cancer. The number of teeth lost was used as a continuous variable and the result of multivariable Cox regression showed that older adults with who had lost more teeth had a significantly increased risk of nasogastric feeding (AHR, 1.01; 95\% CI, 1.003-1.017 $p$-value $=0.008)$.

Sensitivity analysis was performed by excluding people with heart failure, stroke, and cancer to declare the association particularly in the healthier population. The result showed that, among older people without the three comorbidities, those with 10-28 teeth lost also had significantly increased risks of incident nasogastric feeding dependency (AHR, 1.59; 95\% CI, 1.16-2.27; $\mathrm{p}$-value $=0.004)$.

\section{Discussion}

Our study identified a significantly increased risk of nasogastric tube feeding dependency among older adults who had lost 10-28 teeth. Moreover, older age, male gender, consuming vegetables and fruits less than 5-7 days/ week, heart failure, stroke, and cancer were also significant risk factors of nasogastric feeding dependency among older adults.

Teeth loss reduces masticatory function and affects food choice, which serves as an intermittent pathway between malnutrition and diet-related chronic disease [13]. Ioannidou et al. found teeth loss predicted low protein and caloric intake as well as serum albumin level, a biomarker of malnutrition in chronic kidney disease patients [14]. Thus, nasogastric tube feeding may be a solution for nutrition supplements in patients with malnutrition. However, in a study of 891 community-dwelling Japanese elderly, Hiratsuka used serum albumin and high-sensitivity C-reactive protein levels as markers of nutritional status and systemic inflammation to evaluate the relationship between teeth loss and mortality. They found that edentulous and those individuals with 1-9 teeth had higher mortality than those with $>20$ teeth. Nutritional status contributed to the association between teeth loss and mortality in individuals with teeth loss. This study may explain the parts of the biological mechanism between teeth loss and all-cause mortality in older adults [15]. Gaewkhiew reviewed 2 studies and disclosed that the number of teeth lost was associated with a smaller reduction in vegetable and fruit intake [16]. Reduction of dietary fibers increase the incidence of cardiovascular disease. The antioxidants and soluble fibers from vegetables and fruit may protect vessels from atherosclerosis [13]. The same finding was reported by Cheng et al., from a meta-analysis of prospective cohort studies, exhibiting a significant association between teeth loss and risk of cardiovascular disease and stroke [17]. Previous studies also demonstrated that teeth loss is associated with development of cognitive impairment among older adults [18]. Teeth loss also increased the risk of functional disability in the elderly population [19]. Malnutrition, cognitive impairment, and functional disability may lead to nasogastric feeding dependency.

Poor oral health results in teeth loss, which is a complex outcome that reflects of individual's history of dental diseases and national dental service policies [20]. Poor oral health can cause systemic inflammation and immune response and thus lead to cardiovascular diseases and stroke [21]. Poor oral hygiene leads to teeth loss, which contributes to an individual's decline in functional 
Table 1 Baseline characteristics and results of univariate Cox regression analysis ( $n=6165 ; 937$ nasogastric feeding dependency cases)

\begin{tabular}{|c|c|c|c|c|c|}
\hline Demographics & $\begin{array}{l}\text { Total } \\
\text { (\% in column) }\end{array}$ & $\begin{array}{l}\text { Number of } \\
\text { nasogastric } \\
\text { feeding dependency } \\
\text { cases } \\
\text { (\% in row) }\end{array}$ & Hazard Ratio & $(95 \% \mathrm{Cl})$ & $p$-value \\
\hline \multicolumn{6}{|l|}{ Number of teeth lost } \\
\hline 0 & 1660 (26.93\%) & $220(13.25 \%)$ & Ref & & \\
\hline $1-9$ & $2123(34.44 \%)$ & $256(12.06 \%)$ & 1.03 & $0.86-1.24$ & 0.74 \\
\hline $10-28$ & $2382(38.64 \%)$ & $461(19.35 \%)$ & 1.73 & $1.47-2.03$ & $<0.001$ \\
\hline Age in years, mean (SD) & $73.95(6.46)$ & $77.26(6.88)$ & 1.10 & $1.09-1.11$ & $<0.001$ \\
\hline \multicolumn{6}{|l|}{ Gender } \\
\hline Female & $3206(52 \%)$ & $439(13.69 \%)$ & Ref & & \\
\hline Male & $2959(48 \%)$ & $498(16.83 \%)$ & 1.28 & $1.12-1.45$ & $<0.001$ \\
\hline \multicolumn{6}{|l|}{ Body mass index $\left(\mathrm{kg} / \mathrm{m}^{2}\right)$} \\
\hline Underweight $(<18.5)$ & $248(4.38 \%)$ & $55(22.18 \%)$ & 1.69 & $1.28-2.24$ & $<0.001$ \\
\hline Normal weight (18.5-23.9) & $2679(47.29 \%)$ & $415(15.49 \%)$ & Ref & & \\
\hline Overweight (24-26.9) & $1623(28.65 \%)$ & $204(12.57 \%)$ & 0.77 & $0.65-0.91$ & 0.003 \\
\hline Obesity $(\geq 27)$ & $1115(19.68 \%)$ & $168(15.07 \%)$ & 0.95 & $0.80-1.14$ & 0.61 \\
\hline \multicolumn{6}{|l|}{ Marriage status } \\
\hline Married/cohabiting & $4011(65.09 \%)$ & $541(13.49 \%)$ & Ref & & \\
\hline Never married & $123(2.00 \%)$ & $26(21.14 \%)$ & 1.70 & $1.15-2.52$ & 0.01 \\
\hline Widowed/divorced/separated & $2028(32.91 \%)$ & $370(18.24 \%)$ & 1.47 & $1.29-1.68$ & $<0.001$ \\
\hline \multicolumn{6}{|l|}{ Education } \\
\hline Low (elementary or below) & $4146(72.88 \%)$ & $707(17.05 \%)$ & Ref & & \\
\hline Moderate (junior/senior high) & $1068(18.77 \%)$ & $131(12.27 \%)$ & 0.77 & $0.64-0.92$ & 0.01 \\
\hline High (college or above) & $475(8.35 \%)$ & $55(11.58 \%)$ & 0.70 & $0.54-0.93$ & 0.01 \\
\hline \multicolumn{6}{|l|}{ Household income } \\
\hline$<$ US\$952/month & $2848(58.15 \%)$ & $452(15.87 \%)$ & Ref & & \\
\hline US\$952-2222/month & $1439(29.38 \%)$ & $226(15.71 \%)$ & 1.00 & $0.85-1.17$ & 1.00 \\
\hline$>$ US\$2222/month & $611(12.47 \%)$ & $83(13.58 \%)$ & 0.88 & $0.70-1.11$ & 0.28 \\
\hline \multicolumn{6}{|l|}{ Smoking status } \\
\hline Never & $4382(71.09 \%)$ & $613(13.99 \%)$ & Ref & & \\
\hline Current & $839(13.61 \%)$ & $150(17.88 \%)$ & 1.27 & $1.06-1.52$ & 0.01 \\
\hline Former & $943(15.30 \%)$ & $173(18.35 \%)$ & 1.48 & $1.25-1.75$ & $<0.001$ \\
\hline \multicolumn{6}{|l|}{ Alcohol consumption } \\
\hline No & 4170 (77.99\%) & $675(16.19 \%)$ & Ref & & \\
\hline Less than once a week & $740(13.84 \%)$ & $79(10.68 \%)$ & 0.65 & $0.52-0.83$ & $<0.001$ \\
\hline More than once a week & $437(8.17 \%)$ & $68(15.56 \%)$ & 0.80 & $0.62-1.02$ & 0.07 \\
\hline \multicolumn{6}{|l|}{ Vegetable } \\
\hline$<5$ days/week & $422(6.86 \%)$ & $133(31.52 \%)$ & Ref & & \\
\hline 5-7 days/week & $5730(93.14 \%)$ & 793(13.83\%) & 0.41 & $0.34-0.50$ & $<0.001$ \\
\hline \multicolumn{6}{|l|}{ Fruit } \\
\hline$<5$ days/week & 1401 (22.77\%) & $339(24.20 \%)$ & Ref & & \\
\hline 5-7 days/week & 4751 (77.23\%) & $587(12.36 \%)$ & 0.61 & $0.53-0.70$ & $<0.001$ \\
\hline \multicolumn{6}{|l|}{ Betel nut } \\
\hline Never & 5552 (90.07\%) & $844(15.20 \%)$ & Ref & & \\
\hline Current & $223(3.62 \%)$ & $28(12.56 \%)$ & 0.81 & $0.56-1.20$ & 0.30 \\
\hline Former & $389(6.31 \%)$ & $64(16.45 \%)$ & 1.20 & $0.93-1.55$ & 0.16 \\
\hline \multicolumn{6}{|l|}{ Chronic renal failure } \\
\hline No & $5889(95.52 \%)$ & 865 (14.69\%) & Ref & & \\
\hline Yes & $276(4.48 \%)$ & $72(26.09 \%)$ & 2.54 & $2.00-3.23$ & $<0.001$ \\
\hline
\end{tabular}


Table 1 (continued)

\begin{tabular}{|c|c|c|c|c|c|}
\hline Demographics & $\begin{array}{l}\text { Total } \\
\text { (\% in column) }\end{array}$ & $\begin{array}{l}\text { Number of } \\
\text { nasogastric } \\
\text { feeding dependency } \\
\text { cases } \\
\text { (\% in row) }\end{array}$ & Hazard Ratio & $(95 \% \mathrm{Cl})$ & $p$-value \\
\hline \multicolumn{6}{|l|}{ Heart failure } \\
\hline No & 5600 (90.84\%) & 788 (14.07\%) & Ref & & \\
\hline Yes & $565(9.16 \%)$ & 149 (26.37\%) & 2.35 & $1.97-2.80$ & $<0.001$ \\
\hline \multicolumn{6}{|l|}{ Liver cirrhosis } \\
\hline No & 6052 (98.17\%) & 911 (15.05\%) & Ref & & \\
\hline Yes & $113(1.83 \%)$ & $26(23.01 \%)$ & 1.93 & $1.31-2.86$ & $<0.001$ \\
\hline \multicolumn{6}{|l|}{ Stroke } \\
\hline No & 4798 (77.83\%) & 621 (12.94\%) & Ref & & \\
\hline Yes & 1367 (22.17\%) & $316(23.12 \%)$ & 2.13 & $1.86-2.44$ & $<0.001$ \\
\hline \multicolumn{6}{|l|}{ Cancer } \\
\hline No & 5549 (90.01\%) & 822 (14.81\%) & Ref & & \\
\hline Yes & 616 (9.99\%) & 115 (18.67\%) & 1.47 & $1.21-1.79$ & $<0.001$ \\
\hline
\end{tabular}

Abbreviations: $S D$ standard deviation, $\mathrm{Cl}$ confidence interval

capacity, cognitive function, quality of life, and mortality [22-25]. A higher missing teeth count is associated with higher mortality $[15,26]$. Teeth loss reduces mastication force and chewing ability, resulting in choosing soft diet, reduced nutritional intake, and poor nutrition status $[13,16]$. Malnutrition may lead to sarcopenia, frailty, and increase mortality but it is reversible when effective intervention is applied.

In the past, few studies investigated the association between teeth loss and nasogastric tube feeding dependency. Previous research has shown that poor oral health (for example, inability to chew or swallow food, missing teeth, or gum disease) can impair nutrient intake (for example, eating less or low-nutrient meals), leading to poor nutrition and increasing the risk of malnutrition [27]. Malnutrition is a proven indication of nasogastric tube feeding dependency. Previous studies have also indicated that older age and comorbidities, such as dementia and stroke are significant risk factors of nasogastric feeding dependency among older adults [28].

This is a cohort study with longitudinal follow-up for 12 years, which was long enough to detect the incidence of the outcome. The NHIS dataset had collected detailed information of participants, including body mass index, socioeconomic status, and health behaviors. The NHIRD had thorough data on the medical record of the study participants. Nearly all potential confounders were included in the study. There are several limitations of our study. First, some medical conditions that may directly lead to nasogastric feeding dependency, such as parkinsonism with impaired swallowing function, oral cancer, neck and esophageal cancer, may lead to the inability to swell smoothly, causing frequent choking. Second, recall bias may be found when completing the questionnaire. Third, disease comorbidities were recorded but information on disease severity was not obtained. For example, mild stroke without affecting swallowing function may not require nasogastric tube use but severe stroke may lead to swallowing dysfunction and need nasogastric feeding. We did not measure masticatory muscle strength. Severe teeth loss may impair masticatory function, decreasing masseter muscle strength but loss of a few teeth may not. The number of teeth loss were calculated except wisdom teeth and spaces restored with implants. Removable dentures are still classified as missing teeth. Removable dentures can still help chewing function and maintain the strength of the oral muscles. This may underestimate the risk of nasogastric tube feeding dependence caused by missing teeth. Besides, nasogastric tube feeding dependence was defined by the procedure code for three or more times in the outpatient or inpatient medical records consecutively in six months. However, some people may withdraw nasogastric tube feeding six months later if they recover of swallowing function, which may overestimate the risk of tube feeding dependence.

\section{Conclusions}

In conclusion, this study revealed that the number of teeth lost is a significant risk factor of nasogastric tube feeding dependency. It is important to maintain good oral health to prevent periodontal diseases, dental caries, and further teeth loss to prevent the occurrence of nasogastric tube feeding dependency. 
Table 2 Results of multivariate Cox proportional hazards analysis of incidence of nasogastric feeding dependency

\begin{tabular}{|c|c|c|c|}
\hline Demographics & $\begin{array}{l}\text { Adjusted } \\
\text { Hazard Ratio }\end{array}$ & $(95 \% \mathrm{Cl})$ & $p$-value \\
\hline
\end{tabular}

Number of teeth lost $^{\mathrm{a}}$

0 Ref

$1-9 \quad 1.02$

$10-28$

Age (years)

Gender

Female

Body mass index $\left(\mathrm{kg} / \mathrm{m}^{2}\right)$

Underweight $(<18.5)$

Normal weight (18.5-23.9)

Overweight (24-26.9)

Obesity ( $\geq 27$ )

Marriage status

Married/cohabiting Re

Never married $\quad 1.47$

Widowed/divorced/separated 1.06

Education

Low (elementary or below) Ref

Moderate (junior/senior high) $\quad 0.75$

High (college or above) $\quad 0.79$

Household income

$<$ US\$952/month

US\$952-2222/month

>US\$2222/month

Smoking status

Never

Current

Alcohol consumption

No
Less than once a week
More than once a week
vegetable
$<5$ days/week
$5-7$ days/week
ruit
$<5$ days/week
$5-7$ days/week

Betel nut

Never

Current

Chronic renal failure

\begin{tabular}{llll} 
No & Ref & & \\
Yes & 1.46 & $1.03-2.08$ & 0.04 \\
Heart failure & & & \\
No & Ref & & \\
Yes & 1.59 & $1.26-2.01$ & $<0.001$ \\
\hline
\end{tabular}

$0.46-0.76<0.001$

Ref
Table 2 (continued)

\begin{tabular}{llll}
\hline Demographics & $\begin{array}{l}\text { Adjusted } \\
\text { Hazard Ratio }\end{array}$ & $\mathbf{( 9 5 \% \mathrm { Cl } )}$ & $\boldsymbol{p}$-value \\
\hline $\begin{array}{llll}\text { Liver cirrhosis } \\
\text { No }\end{array}$ & $\begin{array}{l}\text { Ref } \\
\text { Yes }\end{array}$ & & \\
Stroke & 1.50 & $0.88-2.58$ & 0.14 \\
$\quad$ No & Ref & & \\
$\quad$ Yes & 1.72 & $1.44-2.05$ & $<0.001$ \\
Cancer & & & \\
$\quad$ No & Ref & & \\
Yes & 1.45 & $1.14-1.86$ & 0.003
\end{tabular}

a Dose-response relationship between numbers of tooth loss and nasogastric feeding was evaluated using the trend test $(P$ for trend $=0.01)$

Abbreviations: $\mathrm{Cl}$ confidence interval

Oral health plays an important part in human health. Common oral illnesses include dental caries, periodontal disease, and teeth loss, which affect about 3.47 billion people in the world [29]. Among adults with disability aged 20-80years in Taiwan, the mean number of remaining teeth was $18.1(\mathrm{SD}=10.9) ; 44.8 \%$ of them had less than 20 remaining teeth, including $13.7 \%$ edentulous participants [30]. Early identification of the oral disease is crucial for the prevention of the occurrence of teeth loss and the following nutrition problems [31, 32], which would reduce risk of nasogastric tube feeding dependency.

\section{Acknowledgements}

Participants jointed the National Health Interview Survey were appreciated.

\section{Authors' contributions}

Study concept and design: C.-C.W., Y.-Y.C, and Y.-J.L. Acquisition of data: K.-C.H. Analysis and interpretation of data: S.-J.W., and Y.-F.Y. Drafting of the manuscript: C.-C.W., and C.-C.C. Critical revision of the manuscript for important intellectual content:Y.-J.L. All authors have read and approved the manuscript.

\section{Funding}

This research received no external funding.

\section{Availability of data and materials}

The data that support the findings of this study are openly available in the Health and Welfare Data Science Center of Ministry of Health and Welfare in Taiwan at https://dep.mohw.gov.tw/dos/np-2497-113.html.

\section{Declarations}

\section{Ethics approval and consent to participate}

This study protocol was reviewed and approved by Research Ethics Committee of the Taipei City Hospital, approval number TCHIRB-10709107-W. Since the datafile contained only de-identified secondary data, the institutional review board waived the requirement for informed consent.

\section{Consent for publication}

Not applicable.

\section{Competing interests}

The authors declare that they have no competing interests. 


\section{Author details}

${ }^{1}$ Division of Chest Medicine, Department of Internal Medicine, Puli Branch of Taichung Veterans General Hospital, Nantou, Taiwan. ${ }^{2}$ Department of Eldercare, Central Taiwan University of Science and Technology, Taichung, Taiwan. ${ }^{3}$ School of Medicine, National Yang-Ming University, Taipei, Taiwan. ${ }^{4}$ Department of Ophthalmology, Taichung Veterans General Hospital, Taichung, Taiwan. ${ }^{5}$ School of Medicine, Chung Shan Medical University, Taichung 402 , Taiwan. ${ }^{6}$ Community Medicine Research Center and Institute of Public Health, National Yang-Ming University, Taipei, Taiwan. ${ }^{7}$ National Chung Hsing University, Taichung, Taiwan. ${ }^{8}$ Department of Anesthesiology, Chi Mei Medical Center, Tainan, Taiwan. ${ }^{9}$ Department of Nursing, Puli Branch of Taichung Veterans General Hospital, Nantou, Taiwan. ${ }^{10}$ College of Nursing Taichung, Central Taiwan University of Science and Technology, Taichung, Taiwan. ${ }^{11}$ Department of Health Care Management, National Taipei University of Nursing and Health Sciences, No.365, Ming-te Road, Peitou District, Taipei City 112, Taiwan.

${ }^{12}$ Section of Infectious Diseases, Taipei City Hospital, Taipei City Government, Taipei, Taiwan. ${ }^{13}$ Institute of Hospital and Health Care Administration, National Yang-Ming University, Taipei, Taiwan. ${ }^{14}$ Department of Exercise Health Science, National Taiwan University of Sport, Taichung, Taiwan. ${ }^{15}$ Division of Endocrinology and Metabolism, Department of Internal Medicine, Puli Branch of Taichung Veterans General Hospital, No.1, Rongguang Rd, Puli Township, Nantou County 545, Taiwan.

Received: 3 June 2021 Accepted: 27 October 2021

Published online: 12 November 2021

\section{References}

1. Shanley C, O'Loughlin G. Dysphagia among nursing home residents: an assessment and management protocol. J Gerontol Nurs. 2000;26(8):35-48.

2. Jardine M, Miles A, Allen J. Dysphagia onset in older adults during unrelated hospital admission: quantitative Videofluoroscopic measures. Geriatrics (Basel). 2018:3(4):66.

3. Smithard DG. Dysphagia management and stroke units. Curr Phys Med Rehabil Rep. 2016;4(4):287-94.

4. Serra-Prat M, Hinojosa G, López D, Juan M, Fabré E, Voss DS, et al. Prevalence of oropharyngeal dysphagia and impaired safety and efficacy of swallow in independently living older persons. J Am Geriatr Soc. 2011;59(1):186-7.

5. The nasogastric tube feeding rate in Taiwan. [https://dep.mohw.gov.tw/ dos/cp-1720-7414-113.html].

6. Schulze J, Mazzola R, Hoffmann F. Incidence of tube feeding in 7174 newly admitted nursing home residents with and without dementia. Am J Alzheimers Dis Other Dement. 2016;31(1):27-33.

7. Mitchell SL, Mor V, Gozalo PL, Servadio JL, Teno JM. Tube feeding in US nursing home residents with advanced dementia, 2000-2014. Jama. 2016;316(7):769-70.

8. Wu T-Y, Majeed A, Kuo KN. An overview of the healthcare system in Taiwan. London J Prim Care (Abingdon). 2010;3(2):115-9.

9. Finucane TE, Christmas C, Travis K. Tube feeding in patients with advanced dementia: a review of the evidence. Jama. 1999;282(14):1365-70.

10. Roche V. Percutaneous endoscopic gastrostomy. Clinical care of PEG tubes in older adults. Geriatrics. 2003;58(11):22-6 28-29.

11. Rofes L, Arreola V, Almirall J, Cabré M, Campins L, García-Peris P, et al. Diagnosis and management of oropharyngeal dysphagia and its nutritional and respiratory complications in the elderly. Gastroenterol Res Pract. 2011;2011:818979.

12. Okamoto N, Morikawa M, Yanagi M, Amano N, Tomioka K, Hazaki K, et al. Association of Tooth Loss with Development of swallowing problems in community-dwelling independent elderly population: the Fujiwara-kyo study. J Gerontol Series A. 2015;70(12):1548-54

13. Walls AW, Steele JG, Sheiham A, Marcenes W, Moynihan PJ. Oral health and nutrition in older people. J Public Health Dent. 2000;60(4):304-7.

14. Ioannidou E, Swede H, Fares G, Himmelfarb J. Tooth loss strongly associates with malnutrition in chronic kidney disease. J Periodontol. 2014;85(7):899-907.

15. Hiratsuka T, Komiyama T, Ohi T, Tanji F, Tomata Y, Tsuji I, et al. Contribution of systemic inflammation and nutritional status to the relationship between tooth loss and mortality in a community-dwelling older Japanese population: a mediation analysis of data from the Tsurugaya project. Clin Oral Investig. 2020;24(6):2071-7.

16. Gaewkhiew P, Sabbah W, Bernabé E. Does tooth loss affect dietary intake and nutritional status? A systematic review of longitudinal studies. J Dent. 2017;67:1-8.

17. Cheng F, Zhang M, Wang Q, Xu H, Dong X, Gao Z, et al. Tooth loss and risk of cardiovascular disease and stroke: a dose-response meta analysis of prospective cohort studies. PLoS One. 2018;13(3):e0194563.

18. Saito S, Ohi T, Murakami T, Komiyama T, Miyoshi Y, Endo K, et al. Association between tooth loss and cognitive impairment in community-dwelling older Japanese adults: a 4-year prospective cohort study from the Ohasama study. BMC oral health. 2018;18(1):142.

19. Komiyama T, Ohi T, Tomata Y, Tanji F, Tsuji I, Watanabe M, et al. Dental status is associated with incident functional disability in communitydwelling older Japanese: a prospective cohort study using propensity score matching. J Epidemiol. 2020;30(2):84-90.

20. Kassebaum NJ, Bernabé E, Dahiya M, Bhandari B, Murray CJ, Marcenes W. Global Burden of Severe Tooth Loss: A Systematic Review and Metaanalysis. J Dent Res. 2014;93(7 Suppl):20s-8s.

21. Silva Junior MF, Batista MJ, de Sousa M. Risk factors for tooth loss in adults: a population-based prospective cohort study. PLoS One. 2019;14(7):e0219240.

22. Sato Y, Aida J, Kondo K, Tsuboya T, Watt RG, Yamamoto T, et al. Tooth loss and decline in functional capacity: a prospective cohort study from the Japan Gerontological evaluation study. J Am Geriatr Soc. 2016;64(11):2336-42

23. Tsakos G, Watt RG, Rouxel PL, de Oliveira C, Demakakos P. Tooth loss associated with physical and cognitive decline in older adults. J Am Geriatr Soc. 2015;63(1):91-9.

24. Gerritsen AE, Allen PF, Witter DJ, Bronkhorst EM, Creugers NH. Tooth loss and oral health-related quality of life: a systematic review and metaanalysis. Health Qual Life Outcomes. 2010;8:126.

25. Peng J, Song J, Han J, Chen Z, Yin X, Zhu J, Song J: The relationship between tooth loss and mortality from all causes, cardiovascular diseases, and coronary heart disease in the general population: systematic review and doseresponse meta-analysis of prospective cohort studies. Bioscience reports. 2019;39(1).

26. Koka S, Gupta A. Association between missing tooth count and mortality: a systematic review. J Prosthodontic Res. 2018;62(2):134-51.

27. El Hélou M, Boulos C, Adib SM, Tabbal N. Relationship between oral health and nutritional status in the elderly: a pilot study in Lebanon. J Clin Gerontol Geriatrics. 2014;5(3):91-5.

28. Mundi MS, Patel J, McClave SA, Hurt RT. Current perspective for tube feeding in the elderly: from identifying malnutrition to providing of enteral nutrition. Clin Interv Aging. 2018;13:1353-64.

29. James SL, Abate D, Abate KH, Abay SM, Abbafati C, Abbasi N, Abbastabar $\mathrm{H}$, Abd-Allah F, Abdela J, Abdelalim AJTL: Global, regional, and national incidence, prevalence, and years lived with disability for 354 diseases and injuries for 195 countries and territories, 1990-2017: a systematic analysis for the Global Burden of Disease Study 2017. Lancet (London, England). 2018;392(10159):1789-858.

30. Pan MY, Hsieh TC, Tai HC, Lin MS, Lin YC, Chen MY. Prevalence of and factors associated with fewer than 20 remaining teeth in Taiwanese adults with disabilities: a community-based cross-sectional study. BMJ open. 2017;7(10):e016270.

31. Cederholm T, Bosaeus I, Barazzoni R, Bauer J, Van Gossum A, Klek S, et al. Diagnostic criteria for malnutrition - An ESPEN Consensus Statement. Clin Nutr (Edinburgh, Scotland). 2015;34(3):335-40.

32. Sánchez-Rodríguez D, Marco E, Schott AM, Rolland Y, Blain H, VázquezIbar O, Escalada F, Duran X, Muniesa JM, Annweiler C. Malnutrition according to ESPEN definition predicts long-term mortality in general older population: Findings from the EPIDOS study-Toulouse cohort. Clin Nutr (Edinburgh, Scotland). 2019;38(6):2652-8.

\section{Publisher's Note}

Springer Nature remains neutral with regard to jurisdictional claims in published maps and institutional affiliations. 